\title{
Adult Emergence of Sitophilus oryzae (L.) (Coleoptera: Curculionidae) in Stored Rice Varieties and Pulses with Broken Grains
}

\author{
J.M. Hettiarachchi*, D.M.S.K. Dissanayaka and L.K.W. Wijayaratne
}

\section{ABSTRACT}

The rice weevil, Sitophilus oryzae, is a serious pest of stored paddy and rice. Much information on its development during the storage of traditional and new improved rice varieties is not found in Sri Lanka. During milling, some percentage of rice is broken, and broken rice generally enhances the development of insects. However, the ability of progeny development of $S$. oryzae in the presence of broken rice particles is unknown. Hence, this study was conducted to assess the progeny development of S. oryzae in different rice and pulse media with a variable percentage of broken grains. Locallyavailable rice varieties, Red Kekulu, Red Samba, Red Heeneti, Kuruluthuda, Suwandel and the pulses, cowpea, greengram and blackgram having different broken percentages were tested for progeny adult emergence at

Department of Plant Sciences, Faculty of Agriculture, Rajarata University of Sri Lanka, Puliyankulama, Anuradhapura, Sri Lanka.

*wollylk@yahoo.com

http://orcid.org/0000-0003-3748-040X

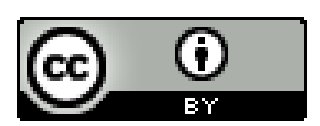

This article is published under the terms of the Creative Commons Attribution 4.0 International License which permits unrestricted use, distribution and reproduction in any medium provided the original author and source are credited.
2, 4 and 6 weeks following initial infestation. The number of adults emerged varied with the grain type, broken percentage and the duration following initial infestation. Greengram $(0-1.5)$ and blackgram (0-0.75) had very low adult emergence while Red Heeneti (0-191.75) and Red Kekulu (0.25-194.67) had the maximum adult emergence. The increase of the broken percentage initially increased the adult emergence and then decreased. The study concluded that $S$. oryzae adult emergence followed a trend of initial increasing and decreasing trend at the latter part in the samples with increasing percentages of broken rice. The adult emergence was higher at intermediate duration following infestation than the first and last durations. Future studies are needed to determine the reasons underlying the variation in the adult emergence across different grain types and broken percentages.

Keywords: Broken grains, Duration of infestation, Progeny development, Pulses, Sitophilus oryzae, Traditional rice varieties

\section{INTRODUCTION}

Agricultural produce is stored mainly for future consumption and trade purposes. Insects infest almost all types of food commodities during 
storage. The quantitative and qualitative losses due to insect infestations have significant impacts on consumers as well as traders, and affect their nutritional requirements and good health. It is estimated that the losses of crop yield in storage can vary as $10 \%$ in temperate areas and as $50 \%$ in tropical areas (Wijayaratne et al., 2018). Of these total post-harvest losses of grains, the damage due to insects can be quite high (Kumar and Kalita, 2017). In Sri Lanka, loss of stored paddy/rice and pulses due to insect attack is frequently reported (Kumari et al., 2020a) and the damage caused by insects in stored paddy/rice may reach nearly $80 \%$ of total storage losses (Wijayaratne et al., 2009; Kumari et al., 2020b). Stored-product insects cause significant economic impacts through nutrient loss; reduced seed viability; contamination of raw or processed food by the presence of living or dead insects, insect fragments, webbing or feces of insects, larval and pupal exuviae; development of hot spots; and health risks such as pathogenic microbial infections (Hill, 1990) and allergic reactions (Campbell et al., 2004). Insect infestations in stored grains can also lead to undesirable taste and odors, and thus make the product inedible (Arthur et al., 2012).
The rice weevil Sitophilus oryzae (L.) (Coleoptera: Curculionidae) is a major pest of stored rice and other cereals in many tropical and subtropical countries (Hill, 1990; Arbogast, 1991; Rees, 2004; Mason and McDonough, 2012). This species has been reported from Sri Lanka in stored paddy (Kumari et al., 2020b). In addition to the feeding by insects during storage of food, the infestation by rice weevil accelerates growth of secondary pests and creates favorable conditions for pathogenic invasion of food (Okram, 2019). Therefore, studies on the protection of stored food from infestation by S. oryzae are important.

The various operations occurred during the processing of paddy/rice can create cracked grains and different-sized particles including flour and dust. These conditions are known to alter the degree of insect infestation. Similarly, the pulses may also be physically damaged during processing, and thus subjected to a different degree of insect infestation (Wijesooriya and Priyadarshana, 2013). However, details on how insect infestation occurs in different rice varieties and pulses consumed in Sri Lanka are not yet available. Unawareness of these facts is a great 
impedance for the adoption of appropriate management methods. Therefore, the objective of this research was to determine the degree of infestation by $S$. oryzae in whole grains and particles of different rice cultivars and pulses.

\section{MATERIALS AND METHODS}

\section{Insects}

The adults of $S$. oryzae reared at $30 \pm 1^{\circ} \mathrm{C}$ and $65 \pm 1 \%$ relative humidity in an incubator (FH-1200, Taiwan Hipoint Corporation, Kaohsiung City) were used in the experiments. Two hundred S. oryzae adults were introduced to 400 $\mathrm{g}$ of red raw rice variety Red Kekulu in a plastic container and covered with a perforated lid. The parent adults were sifted out after 2 weeks. The progeny adults were used in the experiments one month following emergence.

\section{Preparation of Grains}

The rice varieties Red Kekulu, Red Samba, Red Heeneti, Kuruluthuda, Suwandel and the pulses cowpea, greengram and blackgram were used in the study. All the grain types were ground (Mixee-N, Singer India Ltd, New Delhi) and passed through No. $20(850 \mu \mathrm{m})$ and No. 30 $(600 \mu \mathrm{m})$ sieves. The particles retained on sieve No. 30 were mixed as brokengrains with the whole grains to have a final broken-grains as $0 \%, 10 \%, 20 \%$, $40 \%, 60 \%$ or $100 \%$ of the total weight. Cowpea, greengram and blackgram were ground and sifted using No. 10 (2 $\mathrm{mm})$ and No. $20(850 \mu \mathrm{m})$ sieves. The particles that remained on No. 20 sieve were mixed as broken-grains to have different broken proportions as $0 \%$, $10 \%, 20 \%, 40 \%, 60 \%$ or $100 \%$ of the total weight. From a given grain type, $20 \mathrm{~g}$ was weighed and placed inside a plastic vial $(60 \mathrm{~mL})$ and covered with a perforated lid.

\section{Introduction of Adults into Grains}

Twenty S. oryzae adults were introduced into one plastic vial which previously received $20 \mathrm{~g}$ of a particular grain type. These parent adults were removed from the grain sample 2 weeks following introduction. All the grains were maintained at $30 \pm 1^{\circ} \mathrm{C}$ and $65 \pm 1 \%$ relative humidity inside the incubator. Four replicates were tested from each treatment. The progeny adults emerged in each replicate grain sample were counted and removed at. 
every 2-week intervals for 6 consecutive weeks

\section{Experimental Design and Data} Analysis.

Experiments were set up as Completely Randomized Design with four replicates. The $S$. oryzae adults emerged in one replicate of a particular grain type and broken percentage were analyzed using GLM procedure of ANOVA using Statistical Analysis System (SAS Institute, 2002-2008). The means were separated by StudentNewman-Keuls (SNK) test at $p=0.05$.

\section{RESULTS AND DISCUSSION}

\section{Variation in Adult Emergence with} Respect to the Percentage Broken Grain

The adult emergence of $S$. oryzae differed with the grain type $(p<$ $0.0001)$, broken grain percentage in the sample $(p<0.0001)$ and duration following infestation $(p<0.0001)$. Furthermore, the three interactions (grain type $x$ broken percentage), (grain type $\mathrm{x}$ duration) and (broken percentage $x$ duration) were significant $(p<0.0001)$. On the whole, the rice varieties had higher adult emergence than pulses (Tables 1 and 2; Figure 1). With regards to the broken percentage, $S$. oryzae adult emergence increased with the lower percentage of grain fractions in the sample. In general, higher $S$. oryzae adult emergence occurred in $10 \%$ than in other broken percentages. The lowest adult emergence was in 100\% broken grains. In general when the broken percentage increased from $0-100 \%$ the adult emergence followed a trend of initial increasing and subsequent decreasing pattern. This was demonstrated in Red Kekulu and Red Heeneti to a greater extent and in Red Samba and Kuruluthuda varieties with some fluctuations. In contrast, in Suwandel, cowpea, greengram and blackgram, the adult emergence mostly did not differ with the varying percentage of broken grains.

\section{Variation in Adult Emergence with Respect to the Duration}

With regard to the duration, the adult emergence in the middle duration (15-28 days) was higher than first (1-14 days) and last (29-42 days) durations. The higher number of adults emerged in Kuruluthuda (mean 46.4), Red Heeneti (44.8) and Red 
Kekulu (44.1) than other grain types whereas the lowest adults emerged in blackgram (0.153), greengram (0.347), cowpea (1.70) and Suwandel (1.958). The moderate level adult emergence was observed in Red Samba (32.7) (Tables 1 and 2).

In general, all the pulses (cowpea, greengram and blackgram) had very low adult emergence. There was virtually no adult emergence in rice variety Suwandel at 1-14 days, greengram at 29-42 days and blackgram at 15-28 and 29-42 days following removal of parent adults. Furthermore, greengram and blackgram had no significant differences in adult emergence across the different broken percentages throughout all the time durations tested.

The current findings agree with the previous record that $S$. oryzae progeny emergence is higher in larger grain particles. This is believed to be a consequence of the preference of females to oviposit in larger particles (Campbell, 2002). The progeny development of another internal feeder of stored rice Rhyzopertha dominica (F.) on sorghum depends on kernel hardness (Arthur et al., 2020).
Hardness of wheat kernels changes the progeny production in $S$. oryzae as well (McGaughey et al., 1990). The current study revealed that $S$. oryzae progeny development was greater on samples with fewer percentages of broken grains (higher percentage of intact grains). A possible explanation is that $S$. oryzae adults prefer larger grain particles for feeding and oviposition. Therefore, future research needs to be designed to test the hypothesis, if there is a relationship between grain particle size, its hardness and the progeny development in S. oryzae. In contrast, progeny adult emergence in the related species Sitophilus zeamais Motschulsky was higher in fractions of maize than whole maize. Furthermore, the duration from egg laying to the inception of progeny emergence was lower in small particle sizes (Schoonhoven et al., 1974). However, in Oryzaephilus surinamensis (L.), the development was minimum in whole wheat kernels (Fleming, 1988). Contrary to the alteration of progeny with the particle size, the survival of immature rusty grain beetles Cryptolestes ferrugineus (Stephens) is not varied among different particle sizes of cracked corn (Thorne, 1992). The deviations from the previous studies as found in the current findings 
Table 1. Number (mean \pm SE) of Sitophilus oryzae adults emerged at 14, 28 and 42 days following infestation in different fractions of rice varieties Red Kekulu, Red Samba, Red Heeneti, Kuruluthuda and Suwandel (n=4).

\begin{tabular}{|c|c|c|c|c|c|c|c|}
\hline \multirow{3}{*}{ Grain type } & \multirow{3}{*}{$\begin{array}{c}\text { Days } \\
\text { following } \\
\text { initial } \\
\text { infestation } \\
\end{array}$} & \multicolumn{6}{|c|}{ Number of adults emerged (mean $\pm S E)^{a}$} \\
\hline & & \multicolumn{6}{|c|}{$\%$ broken grains } \\
\hline & & $\mathbf{0}$ & 10 & 20 & 40 & 60 & 100 \\
\hline \multirow{3}{*}{ Red Kekulu } & $1-14$ & $2.5 \pm 1.19 \mathrm{~b}$ & $26.67 \pm 7.31 a^{*}$ & $20.75 \pm 6.05 a$ & $4 \pm 1.73 b$ & $1 \pm 0.71 b$ & $0.5 \pm 0.28 b$ \\
\hline & $15-28$ & $112.5 \pm 23.5 b$ & $162.5 \pm 8.76 \mathrm{a}$ & $194.67 \pm 28.24 \mathrm{a}^{*}$ & $63.25 \pm 14.67 \mathrm{c}$ & $53.5 \pm 9.46 c$ & $0.25 \pm 0.25 c$ \\
\hline & $29-42$ & $36.5 \pm 2.33 \mathrm{~b}$ & $66.25 \pm 3.33 a$ & $34.25 \pm 2.21 \mathrm{~b}$ & $23.75 \pm 1.38 \mathrm{c}$ & $23.75 \pm 5.15 c$ & $0.75 \pm 0.48 \mathrm{~d}$ \\
\hline \multirow{3}{*}{ Red Samba } & $1-14$ & $5.75 \pm 2.81 \mathrm{ab}$ & $5.25 \pm 1.70 \mathrm{ab}$ & $18.75 \pm 6.84 a$ & $4 \pm 1.58 \mathrm{ab}$ & $10.5 \pm 3.48 \mathrm{ab}$ & $0.75 \pm 0.48 b$ \\
\hline & $15-28$ & $125 \pm 1.68 \mathrm{ab}$ & $77.5 \pm 13.17 \mathrm{bc}$ & $142 \pm 36.12 a^{*}$ & $46 \pm 0.91 c$ & $86.33 \pm 6.69 b c^{*}$ & $0 \mathrm{~d}$ \\
\hline & $29-42$ & $14.5 \pm 2.75 \mathrm{a}$ & $30.75 \pm 0.63 a$ & $23 \pm 4.18 \mathrm{a}$ & $18.5 \pm 3.92 \mathrm{a}$ & $20.25 \pm 8.64 a$ & $0.5 \pm 0.5 b$ \\
\hline \multirow{3}{*}{ Red Heeneti } & $1-14$ & $6.25 \pm 3.04 \mathrm{~b}$ & $5.75 \pm 1.75 b$ & $18.5 \pm 3.77 \mathrm{a}$ & $1.25 \pm 0.63 b$ & $1.5 \pm 0.86 \mathrm{~b}$ & $0.25 \pm 0.25 b$ \\
\hline & $15-28$ & $135.75 \pm 36.66 \mathrm{ab}$ & $134.25 \pm 2.21 \mathrm{ab}$ & $191.75 \pm 16.54 a$ & $69.25 \pm 11.41 b$ & $72.5 \pm 3.28 b$ & $0 \mathrm{c}$ \\
\hline & $29-42$ & $34.75 \pm 2.75 a$ & $38 \pm 1.08 \mathrm{a}$ & $40.5 \pm 2.9 \mathrm{a}$ & $34 \pm 1.47 \mathrm{a}$ & $21 \pm 1.58 \mathrm{~b}$ & $0.75 \pm 0.48 c$ \\
\hline \multirow{3}{*}{ Kuruluthuda } & $1-14$ & $33.67 \pm 11.84 \mathrm{a}^{*}$ & $56.0 \pm 4.62 \mathrm{a}^{*}$ & $29.75 \pm 6.73 a$ & $29.67 \pm 2.73 \mathrm{a}^{*}$ & $41.33 \pm 7.84 \mathrm{a}^{*}$ & $0.75 \pm 0.25 b$ \\
\hline & $15-28$ & $105 \pm 27.19 a b$ & $142 \pm 28.54 \mathrm{a}$ & $45.75 \pm 5.98 b c$ & $106.75 \pm 18.4 \mathrm{ab}$ & $58 . \pm 3.61 b c^{*}$ & $0.25 \pm 0.25 c$ \\
\hline & $29-42$ & $12 \pm 1.08 \mathrm{~b}$ & $136 \pm 17.22 \mathrm{a}$ & $16 \pm 3.63 b$ & $18.5 \pm 1.55 \mathrm{~b}$ & $0.25 \pm 0.25 b$ & $0.5 \pm 0.28 b$ \\
\hline \multirow{3}{*}{ Suwandel } & $1-14$ & $0 \mathrm{a}$ & $0 \mathrm{a}$ & $1 \pm 0.71 \mathrm{a}$ & $0 \mathrm{a}$ & $0 \mathrm{a}$ & $0 \mathrm{a}$ \\
\hline & $15-28$ & $3.5 \pm 1.85 a$ & $0 \mathrm{a}$ & $0 \mathrm{a}$ & $0.75 \pm 0.48 a$ & $1.75 \pm 1.75 \mathrm{a}$ & $0 \mathrm{a}$ \\
\hline & $29-42$ & $7 \pm 1.22 \mathrm{a}$ & $0.75 \pm 0.48 b$ & $3.25 \pm 0.85 b$ & $9 \pm 0.91 \mathrm{a}$ & $6.5 \pm 1.32 \mathrm{a}$ & $1.75 \pm 0.48 \mathrm{~b}$ \\
\hline
\end{tabular}

${ }^{a}$ For a given variety and duration, means followed by the same letter are not significantly different according to Student-Newman-Keuls (SNK) test following ANOVA at $p=0.05$.

*Only 3 replicates were considered due to the presence of extreme outliers. 
Adult Emergence of Sitophilus oryzae in Stored Rice Varieties and Pulses

Table 2. Number (mean \pm SE) of Sitophilus oryzae adults emerged at 14, 28 and 42 days following infestation in different fractions of pulses cowpea, greengram and blackgram $(n=4)$.

\begin{tabular}{|c|c|c|c|c|c|c|c|}
\hline \multirow{3}{*}{ Grain type } & \multirow{3}{*}{$\begin{array}{c}\text { Days } \\
\text { following } \\
\text { initial } \\
\text { infestation }\end{array}$} & \multicolumn{6}{|c|}{ Number of adults emerged (mean $\pm S E)^{a}$} \\
\hline & & \multicolumn{6}{|c|}{$\%$ broken grains } \\
\hline & & 0 & 10 & 20 & 40 & 60 & 100 \\
\hline \multirow{3}{*}{ Cowpea } & $1-14$ & $1.23 \pm 0.95 \mathrm{a}$ & $0 \mathrm{a}$ & $0.25 \pm 0.25 a$ & $0 \mathrm{a}$ & $1 \pm 0.41 \mathrm{a}$ & $0.25 \pm 0.25 a$ \\
\hline & $15-28$ & $3.5 \pm 1.76 \mathrm{a}$ & $4.25 \pm 2.17 \mathrm{a}$ & $0 \mathrm{a}$ & $1.25 \pm 0.48 a$ & $1.5 \pm 0.96 \mathrm{a}$ & $0 \mathrm{a}$ \\
\hline & $29-42$ & $8.75 \pm 0.63 a$ & $1 \pm 0.41 \mathrm{~d}$ & $2.25 \pm 0.25 c$ & $0.25 \pm 0.25 d$ & $5 \pm 0.41 b$ & $0.25 \pm 0.25 \mathrm{~d}$ \\
\hline \multirow{3}{*}{ Greengram } & $1-14$ & $0 \mathrm{a}$ & $0.25 \pm 0.25 a$ & $0.25 \pm 0.25 a$ & $0 \mathrm{a}$ & $0.5 \pm 0.29 a$ & $1.25 \pm 0.75 \mathrm{a}$ \\
\hline & $15-28$ & $1.5 \pm 0.65 a$ & $0.75 \pm 0.48 a$ & $0.25 \pm 0.25 a$ & $0.25 \pm 0.25 a$ & $0.5 \pm 0.29 a$ & $0 \mathrm{a}$ \\
\hline & $29-42$ & 0 & 0 & 0 & 0 & 0 & 0 \\
\hline \multirow{3}{*}{ Blackgram } & $1-14$ & $0.25 \pm 0.25 a$ & $0.25 \pm 0.25 a$ & $0.25 \pm 0.25 a$ & $0.75 \pm 0.75 a$ & $0.75 \pm 0.48 \mathrm{a}$ & $0.5 \pm 0.29 a$ \\
\hline & $15-28$ & 0 & 0 & 0 & 0 & 0 & 0 \\
\hline & $29-42$ & 0 & 0 & 0 & 0 & 0 & 0 \\
\hline
\end{tabular}

${ }^{a}$ For a given variety and duration, means followed by the same letter are not significantly different according to Student-Newman-Keuls (SNK) test following ANOVA at $p=0.05$. 


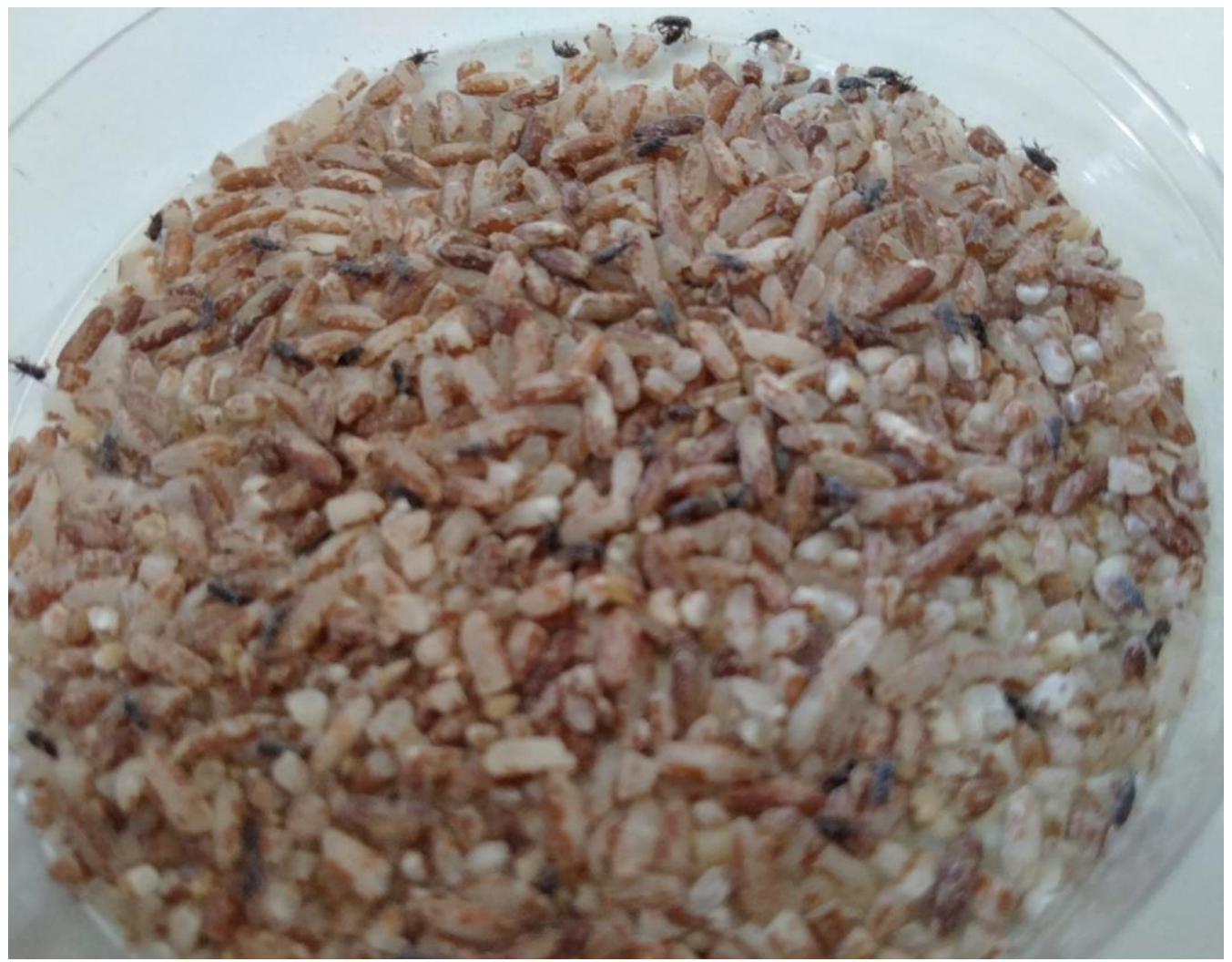

Figure 1. Red raw (Red Kekulu) rice infested with Sitophilus oryzae

would have been caused by the difference in either the grain type (rice vs. maize), insect species (S. oryzae vs. S. zeamais) or both factors, and need to be confirmed in a separate study.

\section{CONCLUSION}

Sitophilus oryzae adult emergence was highest in the rice varieties, Kuruluthuda, Red Heeneti and Red Kekulu. The lowest adult emergence occured in blackgram, greengram, cowpea and Suwandel. The adult emergence in Red Samba was at moderate level. In general, when the broken percentage increases from 0$100 \%$, S. oryzae adult emergence follows an initial increasing and later decreasing pattern. The progeny development of $S$. oryzae was higher at the middle duration following initial infestation compared to the initial and later durations. Future studies are required to test the infestation and progeny emergence of other insect species in grain samples having different broken percentages 
maintained at different durations of storage.

\section{ACKNOWLEDGEMENT}

The authors wish to thank Sri Lanka Council for Agricultural Research Policy (NARP/16/RUSL/AG/01) for the financial assistance provided for the study. The authors also appreciate the assistance from Dr. W.C.P. Egodawatta, Department of Plant Sciences, Rajarata University of Sri Lanka in statistical analysis.

\section{REFERENCES}

Arbogast, R.T. (1991). Beetles: Coleoptera. In: Gorham, J.R. (Ed.), Ecology and Management of Food Industry Pests. FDA technical bulletin 4. Association of analytical chemists, Virginia, USA, pp. 131176.

Arthur, F.H., Ondier, G.O. and Siebenmorgen, T.T. (2012). Impact of Rhyzopertha dominica (F.) on quality parameters of milled rice. Journal of Stored Products Research, 48: 137-142.

Arthur, F. H., Bean, S. R., Smolensky, D., Gerken, A. R., Siliveru, K., Scully, E. D. and Baker, N. (2020). Development of Tribolium castaneum (Herbst) (Coleoptera: Tenebrionidae) on sorghum milling fractions. Journal of Stored Products Research, 87: 101606.

Campbell, J.F. (2002). Influence of seed size on exploitation by the rice weevil, Sitophilus oryzae. Journal of Insect Behaviour, 15: 429-445.

Campbell, J.F., Arthur, F.H. and Mullen, M.A. (2004). Insect management in food processing facilities. Advances in Food and Nutrition Research, 48: 239-295.

Fleming, D. A. (1988). The influence of wheat kernel damage upon the development and productivity of Oryzaephilus surinamensis (L.) (Coleoptera: Silvanidae). Journal of Stored Products Research, 24: 233-236. Hill, D.S. (1990). Pests of Stored Products and their Control. Belhaven press, London.

Kumar, D., and Kalita, P. (2017). Reducing postharvest losses during storage of grain crops to strengthen food security in developing countries. Foods, 6: 8.

Kumari, J. M. P., Wijayaratne, L.K.W., Jayawardena, N.W.I.A. and Egodawatta, W.C.P. (2020a). Quantitative and qualitative losses in paddy, maize and greengram stored under household conditions in Anuradhapura district of Sri Lanka. Sri Lankan Journal of Agriculture and Ecosystems, 2: 99106.

Kumari, J. M. P., Wijayaratne, L.K.W., Jayawardena, N.W.I.A. and Egodawatta, W.C.P. (2020b). Household level paddy storage and 
insect infestation of paddy, maize and mungbean in Anuradhapura district of Sri Lanka. Sri Lankan Journal of Agriculture and Ecosystems, 2: 70-80.

Mason, L.J. and McDonough, M. (2012). Biology, behavior, and ecology of stored grain and legume insects. In: Hagstrum, D.W., Philips, T.W., Cuperus, G. (Eds.), Stored Product Protection. Kansas state university agricultural experiment station and cooperative extension service, pp. 7e20. http://www.ksre.ksu.edu/bookstore / pubs/S156.pdf.

McGaughey, W. H., Speirs, R. D. and Martin, C. R. (1990). Susceptibility of classes of wheat grown in the United States to stored-grain insects. Journal of Economic Entomology, 83: 1122-1127.

Okram, S. and Hath, T.K. (2019). Biology of Sitophilus oryzae (L.) (Coleoptera: Curculionidae) on stored rice grains during different seasons in Terai agro-ecology of West Bengal. International Journal of Current Microbiology and Applied Sciences, 8: 1955-1963.

Rees, D. (2004). Insects of Stored Products. CSIRO publishing Australia and Manson publishing Ltd, UK.

SAS Institute (2002-2008). The SAS system for windows, Release 9.1. Cary, NC, USA.

Schoonhoven, A. V., Mills, R. B. and Horber, E. (1974). Development of
Sitophilus zeamais Motschulsky, in maize kernels and pellets made from maize kernel fractions. Journal of Stored Products Research, 10: 73-80.

Thorne, J. E. (1992). Survival of immature rusty grain beetles (Coleoptera, Cucujidae) on various particle sizes of cracked corn. Journal of Entomological Science, 27: 65-70.

Wijayaratne, L.K.W., Arthur, F.H., and Whyard, S. (2018). Methoprene and control of stored-product insects. Journal of Stored Products Research, 76: 161-169.

Wijayaratne, L.K.W., Fernando, M.D., and Palipane, K.B. (2009). Control of insect pests under ware-house conditions using smoke generated from partial combustion of rice (paddy) husk. Journal of the National Science Foundation of Sri Lanka, 37: 125-134.

Wijesooriya, W.A.N., and Priyadarshana W.H.D. (2013). Structure, conduct and performance of rice milling industry in Polonnaruwa and Hambantota districts of Sri Lanka. Research Report. Hector Kobbekaduwa Agrarian Research and Training Institute. 